\title{
Lexis
}

Journal in English Lexicology

HS 1 | 2009

Lexicology \& Phonology

\section{Double -er suffixation in English: morphological, phonological and sociolinguistic reflections}

Jim Walker

\section{(2) OpenEdition}

Journals

\section{Electronic version}

URL: http://journals.openedition.org/lexis/867

DOI: $10.4000 /$ lexis.867

ISSN: 1951-6215

\section{Publisher}

Université Jean Moulin - Lyon 3

\section{Electronic reference}

Jim Walker, « Double -er suffixation in English: morphological, phonological and sociolinguistic

reflections », Lexis [Online], HS 1 | 2009, Online since 17 September 2009, connection on 01 May 2019. URL : http://journals.openedition.org/lexis/867 ; DOI : 10.4000/lexis.867

\section{(c) (i) (9)}

Lexis is licensed under a Creative Commons Attribution-NonCommercial-NoDerivatives 4.0 International License. 


\title{
Double -er suffixation in English: morphological, phonological and sociolinguistic reflections
}

Jim Walker ${ }^{2}$

\begin{abstract}
In this article, I examine a relatively little discussed phenomenon which appears to be increasingly prevalent in contemporary English, namely the reduplication of the deverbal -er suffix on phrasal verbs to produce forms such as washer upper, looker outer and asker outer. I look at some of the morphological, diachronic and sociolinguistic questions which arise, before positing the hypothesis that this reduplication is not a purely morphological phenomenon, but in fact owes a great deal to phonological causes, and in particular euphonic considerations.
\end{abstract}

Key-words: morphology - phonology - euphony - phrasal verbs - suffixation - reduplication - colloquial English - linguistics

\section{Résumé}

Dans cet article, j'examine un phénomène morphologique de l'anglais contemporain qui semble ne pas avoir attiré l'attention de beaucoup de linguistes, mais qui semble néanmoins de plus en plus fréquent, à savoir la reduplication du suffixe déverbal -er sur les verbes à particule pour générer des formes telles que washer upper, looker outer and asker outer. Je passe en revue un certain nombre des questions morphologiques, diachroniques et sociolinguistiques posées par cette suffixation, avant d'émettre l'hypothèse que nous sommes en face ici non pas d'un procédé purement morphologique, mais d'un phénomène qui doit beaucoup à des considérations phonologiques, et en particulier euphoniques.

Mots-clés : morphologie - phonologie - euphonie - verbes à particule - suffixation reduplication - anglais non-standard - linguistique

\footnotetext{
2 Université Lumière - Lyon 2. Centre de Recherche en Terminologie et Traduction - EA 4162: jim.walker@univ-lyon2.fr
} 
In this article, I shall be taking a look at a morphological feature of contemporary English which has received relatively, and surprisingly, little coverage in the literature, as far as I can ascertain. It is a phenomenon which I have chosen to refer to tentatively as double -er suffixation, pending a better term, whereby certain phrasal verbs can give rise to nominalised derivatives with the -er suffix both on the verb and on the accompanying particle, such as washer upper. I shall have a number of morphological, phonological and sociolinguistic reflections to make, before concluding that understanding this phenomenon may require going beyond the normal bounds of linguistic analysis that we usually set for ourselves.

The Oxford English Dictionary, in the entry on -er, suffix ${ }^{1}$, states:

In mod.Eng. they [-er derivatives] may be formed on all vbs., excepting some of those which have agent-nouns ending in -or, and some others for which this function is served by ns. of different formation (e.g. correspond, correspondent).

The same suffix can also appear on nouns, as the examples hatter, slater, lawyer, villager, Londoner and so forth demonstrate. More interesting, and more germane to the central thrust of the argument I wish to set forth here, are two other uses of this self same suffix, noted "-er, suffix" by the $O E D$, numbered 1 and 2 below, and in particular the "-er, suffix 6 " which I have numbered 3 . I provide these quotes here as preliminary evidence that the double -er suffix may not be a purely morphological phenomenon, a point I expand on below. The key words to note are "colloquial", "unmeaning" and "jocular".

1. a class of words chiefly belonging to mod. colloquial language, and denoting things or actions, as header, back-hander, fiver, out-and-outer, three-decker.

2. In several instances -er has the appearance of being an unmeaning extension of earlier words ending in -er denoting trades or offices caterer, fruiterer, poulterer, upholsterer.

3. Introduced from Rugby School into Oxford University slang, orig. at University College, in Michaelmas Term, 1875; used to make jocular formations on ns., by clipping or curtailing them and adding -er to the remaining part, which is sometimes itself distorted. Among the earliest instances are FOOTER $n .{ }^{1} 3 \mathrm{~b}$ (= football) (1863), RUGGER (1893) etc. [...] 1904 Daily Chron. 25 Mar. 4/7 Mr. Gladstone was 'the Gladder'. An undergraduate left his 'bedder' in the morning to eat his 'brekker' in his 'sitter'; later he attended a 'lecker', and in the afternoon he might run with the 'Toggers' (torpid races) or take some other form of 'ecker'.

If we focus for the moment on the verbal derivatives, there are three logical possibilities for using the $-e r$ suffix with phrasal verbs, all of which are attested ${ }^{1}$ :

1. V-er + particle: passer-by / runner-up / hanger on / opener up

- Every fool knows that lookers-on see most of the game.

- He was a great mucker-in and as such soon earned respect from those younger and greener as well as his elders and betters.

2. $\mathrm{V}+$ particle + -er:

- We had finally reached Hyde Park, where the Committee had arranged for the sit-downers to meet before marching to Whitehall.

- The hang-arounders' cheerful chirrups.

\footnotetext{
${ }^{1}$ Unless otherwise indicated, all of the examples in the article are taken from the $O E D$.
} 


\section{3. $\underline{\mathrm{V}-e r+\text { particle }+-e r}$ :}

- For every fling-arounder, there is a busy little picker-upper.

- With his number sucker-upper. He's a number mucker-upper. ${ }^{2}$

- I am a very outgoing girl who is always the asker-outer in relationships. ${ }^{3}$

It is of course these latter examples that are of interest here, where there appears to exist a case of reduplicated suffixation in contemporary English, the -er suffix being appended both to the verb and its particle. The first question which naturally arises is to enquire as to whether or not we are dealing here with nonce formations. In one sense, this is not a particularly interesting question, in that nonce formations abide by more general linguistic principles and consequently there is no logical reason to disregard them and to sweep them under the linguistic carpet. There is nevertheless a temptation to discount nonce formations as inherently uninteresting because of their unique character. My position would be to say that whether or not they are nonce formations is neither here nor there in an assessment of their interest in more general linguistic terms. On the other hand, it would be difficult to draw any major conclusions on the basis of phenomena that prove to be vanishingly rare, and for this reason the first step must be to ascertain whether or not this phenomenon is widespread to any degree.

The following table shows the results of a brief and preliminary Internet survey conducted to answer this question. The verbs in question were taken from an on-line list of phrasal verbs ${ }^{4}$, and comprise all of the phrasal verbs beginning with the letter ' $A$ '. The first of the two figures is the number of hits obtained on a Google search conducted on 15 January 2009 using the string "Verb+ER Particle+ER" (i.e. accounter forer, acher forer, acter on(n)er, etc.). This figure has been adjusted, where possible and feasible, to account for repeated hits and false positives, notably spelling mistakes. The second of the figures is the number of hits for the same string using the GoogleBooks search engine, the aim being to weed out as many of the hits from blogs, forums and other similar sites as possible.

\begin{tabular}{|l|l|l|}
\hline ACCOUNT FOR & 0 & 0 \\
\hline ACHE FOR & 0 & 0 \\
\hline ACT ON & 0 & 0 \\
\hline ACT OUT $^{\mathbf{5}}$ & $\mathbf{1 6 9}$ & $\mathbf{6 9}$ \\
\hline ADD UP & $\mathbf{2 5 1}$ & $\mathbf{2 9}$ \\
\hline ACT UP & $\mathbf{7}$ & $\mathbf{0}$ \\
\hline AIM AT & 0 & 0 \\
\hline ALLOW FOR & 0 & 0 \\
\hline ANGLE FOR & 0 & 0 \\
\hline ANSWER BACK & 3 & 0 \\
\hline ANSWER FOR & 0 & 0 \\
\hline ARGUE OUT & 0 & 0 \\
\hline ASK AFTER & 0 & 0 \\
\hline ASK AROUND & $\mathbf{1}$ & $\mathbf{0}$ \\
\hline
\end{tabular}

\footnotetext{
${ }^{2}$ The song which introduces the Numbertaker, a character from BBC children's television programme The Numberjacks.

${ }^{3} \mathrm{http}: / / w w w . m n d a i l y . c o m / 2008 / 10 / 14 /$ dr-date

${ }^{4} \mathrm{http}: / /$ www.usingenglish.com/reference/phrasal-verbs

5 The relatively large number of Google Book hits is due to "acter outer" being a term in psychoanalysis to refer to a particular behavioural disorder.
} 


\begin{tabular}{|l|l|l|}
\hline ASK FOR & $\mathbf{3 1}$ & $\mathbf{0}$ \\
\hline ASK IN & 0 & 0 \\
\hline ASK OUT & $\mathbf{2 9 4}$ & $\mathbf{0}$ \\
\hline ASK OVER & 0 & 0 \\
\hline ASK ROUND & 0 & 0 \\
\hline AUCTION OFF & 0 & 0 \\
\hline
\end{tabular}

Table 1: Google hits of phrasal verbs with reduplicated -er, beginning with ' $A$ '

The first remark to be made is that out of 20 possible words, 6 have attested reduplicated suffixal forms. Preliminary investigations further into the alphabet would seem to indicate that this ratio approximately holds good throughout the corpus, though this necessitates confirmation. Any conclusions on this evidence would be laughably fragile, of course, but it would appear while the form is rare, it shows some degree of productivity. Also worthy of note, en passant, and something to which I will return, is the phonological form of the attested verbs: five out of six have a particle that finishes with an occlusive, and five out of six are composed of two monosyllabic forms.

We turn now to see how the reduplicated forms fare in dictionaries, and in particular in the $O E D$. There are a total of 14 reduplicated -er forms to be found in the $O E D$, which can be divided into three categories:

1. Words which are granted their own entry:

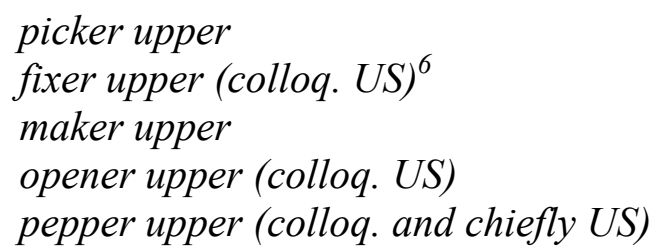

2. Words which are the subject of a sub-entry of the verb or derived noun:

looker upper
mucker upper
tearer downer (colloq.)
tidier upper (colloq.)
waker upper (colloq.)
warmer upper
washer upper (colloq.)

3. Words which feature in citations for other entries, and are subject to no exemplification or discussion:

chatter upper (in the entry sex)

helper outer (in pantomime)

While it might be argued that 14 examples in a corpus as extensive as the Oxford English Dictionary is hardly evidence of a frequent pattern, it is nevertheless a figure which puts paid to the notion that these are nonce forms.

\footnotetext{
${ }^{6}$ Where the $O E D$ gives an indication as to geographical origin and style, this has been indicated.
} 
Also important to note is that of the 14 forms, all 14 have particles with a final occlusive and 13 are a combination of monosyllabic verb with monosyllabic particle, such that when the suffix is appended, we are left with a pattern of four syllables, strong/weak/strong/weak. Even the apparent exception to this, opener upper < open up, when suffixed, is likely to be pronounced [,əupnə-r-' $\Lambda$ pə] with four syllables, and is thus only partially exceptional.

Before returning to the issue of phonology, we need to continue assessing whether or not this pattern is widespread by seeing to what extent it has been picked up on in the linguistic literature. Once again, the picture is somewhat mixed. There are indeed references to such reduplicated forms, stretching back over a number of decades, thus suggesting that the pattern is not original. These references, however, are rather disparate, an indication that it has yet to be taken seriously as an object of linguistic analysis or that such analysis has proved elusive. For example, Bauer [1983: 289] says they "tend to feel very clumsy, and as a result tend to be used mainly in colloquial speech"”. Similarly, Blevins [2006: 527] refers to them as "colloquial". In both cases, it is hard to escape the suspicion that the term "colloquial" is used rather dismissively, as if the very fact that something is colloquial means that it is somehow less worthy of serious consideration.

This last remark is borne out by the following citation, which also presents the advantage of being somewhat older, thus providing the perfect transition to a brief consideration of the diachrony of reduplicated -er suffixation. In a pre-war article, Wentworth [1936] refers to:

The current, popular, grotesque way of forming new low-colloquial and slang compound nouns of agency - adding -er to an intransitive verb and another -er to its adverb, e.g., maker-upper - is (judging tentatively from eighteen documented and countless undocumented instances of use) national in occurrence, journalistic in origin, collegiate in vogue, and economical in expression of ideas.

The pattern receives brief mentions elsewhere in the literature (Bolinger [1971: 116] "popular coinages", Busuttil n.d., 145, for example), but to my knowledge, there is only one full scholarly article devoted entirely to the issue, that by Bert Cappelle, to which I will return.

Another question which arises is whether or not we are dealing with something that is well established or which seems to be relatively novel. A number of sources, discussed in B. Cappelle (forthcoming), would seem to indicate that this is a purely twentieth century phenomenon, with a peak in popularity between the 1920s and the 1940s. The attestations in the $O E D$, in particular, as well as the quote from Wentworth [1936] above would seem to support this view, along with the remarks of no less an authority than H. L. Mencken [1956: 381], who wrote in 1956 that:

There was a transient fashion in the second lustrum of the 30s for nouns on the order of maker-upper, compounded of a verb and an adverb, with -er added to each. A somewhat

\footnotetext{
${ }^{7}$ Despite the very high esteem in which I hold Bauer's work, this strikes me as a rather odd statement. First of all, it is by no means clear why a correlation should be established between clumsiness and colloquialness. Second, the logic would seem to be backwards. It is not hard to understand how some people, speaking from the purist corner, may wish to claim that because something is colloquial, it is ipso facto clumsy, but more difficult to see why something which is clumsy would come to be colloquial, as Bauer seems to be arguing. Finally, I shall try to argue that the popularity of these formations arises precisely because they are NOT clumsy, however we may wish to qualify that notion.
} 
similar fashion, in the days before the Civil War, had produced forms such as come outer.'

Further support to this position is provided by a search on the TIME corpus ${ }^{8}$ of all the nominalised phrasal verbs with 'up', which produced the following results:

\begin{tabular}{|lc|}
\hline FIXER-UPPER & 7 hits \\
BUILDER-UPPER & 3 \\
STIRRER-UPPER & 3 \\
CHECKER-UPPER & 2 \\
BUSTER-UPPER & 2 \\
CLEANER-UPPER & 2 \\
PEPPER-UPPER & 2 \\
WHIPPER-UPPER & 1 \\
UPPER-UPPER & 1 \\
TRIPPER-UPPER & 1 \\
SOFTENER-UPPER & 1 \\
PICKER-UPPER & 1 \\
PANTS-PULLER-UPPER & 1 \\
DISHER-UPPER & 1 \\
CHEERER-UPPER & 1 \\
TOTAL & $\mathbf{2 9}$ \\
\hline
\end{tabular}

Table 2: Upper phrasal verbs in the TIME corpus

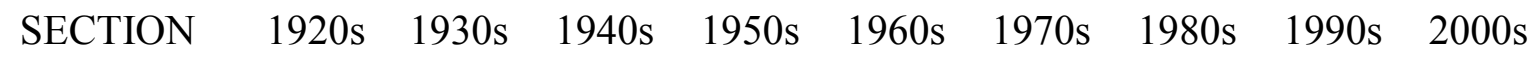

$\begin{array}{cccccccccc}\text { PER MIL } & \mathbf{0 . 0} & \mathbf{0 . 4} & \mathbf{0 . 5} & \mathbf{0 . 2} & \mathbf{0 . 1} & \mathbf{0 . 1} & \mathbf{0 . 2} & \mathbf{0 . 2} & \mathbf{0 . 8} \\ \text { SIZE (MW) } & 7.6 & 12.7 & 15.5 & 16.8 & 16.1 & 13.6 & 11.4 & 9.7 & 6.4 \\ \text { FREQ } & 0 & 5 & 8 & 4 & 2 & 1 & 2 & 2 & 5\end{array}$

Table 3: Relative frequency of upper phrasal verbs in the TIME corpus ${ }^{1}$

\footnotetext{
${ }^{8}$ http://corpus.byu.edu/time/x.asp
} 
The results here are very much in line with previous discussion, with one notable exception. First, we have an overwhelming majority of monosyllabic verbs (14 out of the 15 different verbs, the only exception being soften up, but for which the same remarks apply as for open up above). Second, it does indeed appear as if there was a peak in the use of reduplicated phrasal verbs in the 1940s and that they began to tail off thereafter. The new point to note, however, is the dramatic increase in the pattern after 2000 . We can only speculate as to why this may be: genuine revitalisation of a morphological rule which appeared to be disappearing, or colloquialisation of the magazine TIME, such that formations of this kind, without ever having been under threat in speech, were able to find their way more readily into the pages of the magazine? I have argued elsewhere [Walker 2008] that many linguistic changes which we take to be innovative are equally likely to be the result of the emergence into the public arena of nonstandard varieties which previously had little or no public exposure. It would therefore be extremely interesting to delve further into the diachrony of this reduplicated form.

Any assessment of the dynamic for any of the pattern would of necessity take sociolinguistic aspects into account. All of the literature on this pattern agrees that it should be regarded as a "nonstandard" form. This is something which is only rarely evident in the corpus, with only a handful of examples such as the following, in which the author/speaker overtly indicated doubt as to see status of the form being used.

- The Sharp El-1801A electro-mechanical "adder-upper" on my desk tells me that I spent about $\$ 539.00$ on this project, but you know how those calculators lie! ${ }^{9}$

- I was wondering what type of music would be great pumper upper (if that's a word) ${ }^{10}$.

- Guys are usually the asker outer (is that a word?) ${ }^{11}$.

My initial thinking on this matter is that it is perhaps the relative rarity and jocularity of these forms which leads to the impression of nonstandardness, rather than the pattern per se, but this again is another hypothesis to be followed up.

Clearly, the most obvious linguistic questions which arise when taking a cursory glance at these forms are morphological in nature. If the suffix is being applied in two different places, what does this tell us about the headedness of phrasal verbs? Do they have two heads? Should particle verbs be seen as complex words? What of synthetic compounds, such as letter answerer backer or Bush agreer-wither - do reduplicated -er patterns have any particular restrictions in the way they form compounds? How does the syntactic nature of the particle (adverb or preposition) influence the pattern? How are these forms pluralised, and what light does the answer to this question throw on the previous questions? Why is reduplicated -er so much more common than its counterpart, reduplicated -ee (294 hits for asker outer, 2 hits for askee outee, for instance).

I shall only attempt an answer to the last of these questions, and in so doing shall advance the hypothesis that in fact reduplicated -er is not primarily a morphological phenomenon, but owes its existence in popularity to phonological phenomena, and more particularly to euphony. More precisely, I feel an argument can be put forth, whereby the second -er in the reduplication can be seen as being entirely devoid of meaning, and therefore

\footnotetext{
${ }^{9} \mathrm{http} / / / \mathrm{www}$. surplusrifle.com/shooting/oddshot1/index.asp - use of inverted, is to highlight the fragile work status.

${ }^{10} \mathrm{http}$ //ar.answers.yahoo.com/question/index?qid=20080427123036AAET94X - there are only 7 hits on Google for a reduplicated -er phrasal verb followed by the string "if that's a word".

${ }^{11} \mathrm{http}$ ://answers.yahoo.com/question/index?qid=20080514095425AAGwXuS - 1 hit.
} 
not as a morpheme at all, somewhat akin to the second -er in caterer or the purely jocular -er of rugger, as discussed above.

To doubt that doubler upper nouns, as Cappelle cleverly dubs them, are not the result of a morphological rule might on the face of it seem a rather ridiculous proposition. As we hinted in the introduction, the suffix -er is a staple of textbooks on word formation in English, because it is so productive and transparent in its usage. Cappelle provides an extremely enlightening attempt to explain the existence of such nominalised forms in morphological terms. But we need, I think, to give serious consideration to the idea that these forms have gained a certain popularity for phonological reasons, and more particularly for reasons of euphony, not unlike ablaut reduplication forms. Cappelle regards such an attempt as "linguistically naïve", but there is some evidence that needs careful consideration, evidence of two kinds: metrical patterns and retriplication.

The vast majority of double suffixed phrasal verbs involve a monosyllabic verb and monosyllabic particle, as we have seen, which when suffixed produce a four syllable structure with alternating strong and weak syllables. There is strong evidence that this metrical pattern is universal in children's counting rhymes [Arleo 2001], among other things, and the possibility that in some sense, the output of the affixation process is pleasing to the ear is a factor in its extension should not be dismissed out of hand. There is clearly something euphonic about riff raff, splish splash, ping pong and other ablaut reduplicates, just as there is with the childish initial /w/ reduplication (milky-wilky, hurty wurty), and the same may be true of reduplicated -er suffixes. Further evidence, or at least food for thought, in favour of this proposal is that while phrasal verbs do admit a double -ee suffix, in examples such as "Can anyone tell me what my askee outee meant when he said 'well, I am kind of splitting up with my girlfriend right now""12, these are emphatically rarer than the -er counterpart, as we saw above. While other explanations may well be possible, it is hard to imagine that the obligatory final stress born by -ee is not a factor.

Exhibit B in the case for an explanation of double -er based in part on euphonic considerations is a phenomenon I propose to call -er retriplication, i.e. whereby a phrasal verb actually bears the -er suffix three times, once on the verb and twice on the particle. Examples include:

They cram into the restaurant hoping to get a glimpse of the famous restaurant closerdownerer. ${ }^{13}$

I'm very much a dreamer and a tryer-outerer i.e. being a wannabe geek. ${ }^{14}$

This third -er surely does not lend itself to morphological analysis, and yet it is by no means very rare. A Google search on 13 March 2009 showed 3,880 hits for upperer, the vast majority of which appeared to be genuine phrasal verb derivations. That this third -er is not felt by speakers to be anything other than a phonetic addendum is evidenced by occasional

\footnotetext{
${ }^{12} \mathrm{http}: / /$ manslations.com/2009/02/23/is-he-shy-or-just-not-interested/ accessed on 23 January 2009.

${ }^{13} \mathrm{http}$ ://forums.2kgames.com/forums/archive/index.php/t-1022-p-2.html accessed on 24 January 2009.

$14 \mathrm{http} / / /$ kornfest.com/userstags/hobbies/i039m-very-much-dreamer-and-tryer-outerer-ie-being-wannabe-geek accessed on 3 February 2009.
} 
spellings such as "Are you a good adder-upper-rah?? or do you need a calculator?", or "U can be my advice giver-outer-rah"

That -er may in many cases not be a morpheme, but a useful euphonic tool in that it supplies an additional syllable necessarily pronounced with a schwa, is also suggested by more outlandish and playful inventions such as "It is handy having a spider-getter-outer-oferthe-houser around." 17 , or "Dishwasher getter outer ofer", which is a creation of the author, but one that has been used without attracting so much as a murmur of protest from fellow English speakers.

To conclude then: I wish to hypothesise that reduplicated -er phrasal verbs are the results of a pseudo-morphological process owing a great deal to euphonic considerations. This is a hypothesis which needs to be sketched out in far greater detail in forthcoming research, and one which may well prove unfounded, but we might be well advised to pay more attention to the question of "ear-catchiness" in our analyses of linguistic structures.

\section{Bibliography}

ARLEO Andy, "Do children's rhymes reveal universal metrical patterns?", Bulletin de la Société de Stylistique Anglaise 22, 2001: 125-145.

Aroui J.-L. and ArLeo A. (eds.), Towards a Typology of Poetic Forms: from linguistic structure to metrics and beyond, Amsterdam, John Benjamins (forthcoming).

BAUER Laurie, English Word-Formation, Cambridge, Cambridge University Press, 1983.

BLEVINS J. P., "English inflection and derivation", The handbook of English linguistics, Malden, MA, Blackwell, 2006: 507-536.

Bolinger Dwight, The Phrasal Verb in English, Boston, Harvard University Press, 1971.

BusuTtIL Pierre, "Est-il réellement possible de parler de création en matière de lexicologie ? Quelques éléments de réflexion sur la pensée de l'origine, la langue anglaise et la lexicogenèse », http://web.univ-pau.fr/psd/AfficheOrigin2.pdf

CAPPELLE Bert, "Rule based versus usage based knowledge of doubler-upper nouns: A false opposition", 2006, https:/www2.kuleuvenkortrijk.be/nl/Onderzoek/Letteren/OnderzoekTaalkunde/FEST/DescriptiveEnglishGram mar/bert-cappelle/doubler-upper\%20nouns.pdf

MENCKEN Henry Louis, The American language; an inquiry into the development of English in the United States. Supplement I, New York, A. A. Knopf, 1956.

WALKER Jim, "The footballer''s perfect - are footballers leading the way?" in LAVRIC Eva/Pisek, Gerhard/Skinner, Andrew/Stadler, Wolfgang (eds.), The Linguistics of Football, Language in Performance, Band 38: 24-38.

Wentworth H., "On Adding the Suffix of Agency,-Er, to Adverbs", American Speech 11, no. 4, 1936: 369-370.

\footnotetext{
${ }^{15}$ http://answers.yahoo.com/question/index; ylt=AomuzLIpZpOburvdxG9zFcTty6IX;_ylv=3?qid=200704192317 21AAZA2Lu\&show=7\#profile-info-6185ce64ac6d19a3788c83d88d5e8998aa accessed on 3 February 2009.

16 http://10st-with0ut-y0u.spaces.live.com/Blog/cns!1peyj5-FclMD5DylgB279d1A!778.entry accessed on 3 February 2009.

${ }^{17} \mathrm{http} / / /$ sabrinafaire.com/2004/08/06/thumbs-and-weddings-and-grandmothers-oh-my/ accessed on 3 February 2009.
} 